\title{
Cadaver Dissection Is Obsolete in Medical Training! A Misinterpreted Notion
}

\author{
Ismail Memon
}

Basic Sciences Department, College of Science and Health Professions, King Saud bin Abdulaziz University for Health Sciences, Riyadh, Kingdom of Saudi Arabia

\section{Significance of the Study}

- Since the inception of the modern medical curriculum, anatomy teaching and cadaver dissection (CD) have been diluted or reallocated in medical training. Anatomists, surgeons, and medical educationists have published different opinions on the status of CD. This review presents the status of CD in traditional and modern curricula, undergraduate and postgraduate medical education, surgical training, and elective courses. It also provides information on the relevance of CD to medical training. This can help stakeholders to include anatomy and CD in a justified manner in medical training.

\section{Keywords}

Anatomy teaching · Medical curriculum · Cadaver dissection · Surgery training

\section{Abstract}

Cadaver dissection (CD) is considered a tool for studying the structural details of the human body. Lately, conflicting opinions regarding the utility of this modality in medical training have been published in medical literature. This review of the literature examines the status of anatomy teaching with $C D$ in traditional, modern, and postgraduate medical training across the world. Literature published in the English language on topics related to CD in the past 3 decades was scrutinized using different search engines. About 200 full texts were reviewed. We describe how medical schools have continued to include CD in anatomy teaching in the traditional or modified form. Medical schools that stopped
\end{abstract}

\begin{tabular}{ll}
\hline KARGER & $\begin{array}{l}\text { (c) } 2018 \text { The Author(s) } \\
\text { Published by S. Karger AG, Basel }\end{array}$ \\
E-Mail karger@karger.com & $\begin{array}{l}\text { This is an Open Access article licensed under the Creative Commons } \\
\text { Attribution-NonCommercial-4.0 International License (CC BY-NC) } \\
\text { (http://www.karger.com/Services/OpenAccessLicense), applicable to } \\
\text { the online version of the article only. Usage and distribution for } \\
\text { commercial purposes requires written permission. }\end{array}$
\end{tabular}

or decreased CD have learnt from their experiences, and have restarted it in modified forms by integrating it vertically with medical training. In addition, CD activities have increased in postgraduate anatomy courses, surgery training, and voluntary/optional CD programs. CD, when integrated vertically, still has a part to play in medical training in modified ways. This overview may help curriculum designers to place CD in medical curricula and training programs in a justified manner.

(C) 2018 The Author(s)

Published by S. Karger AG, Basel

\section{Introduction}

Cadaver dissection (CD) started in 300 BC [1] and by the 15 th century, it was considered a tool for studying the structural details of the human body. The first documented CD by a medical student was performed in the 16th 
Fig. 1. Organogram illustrating the status of cadaver dissection in the curriculum and as voluntary/optional activities.

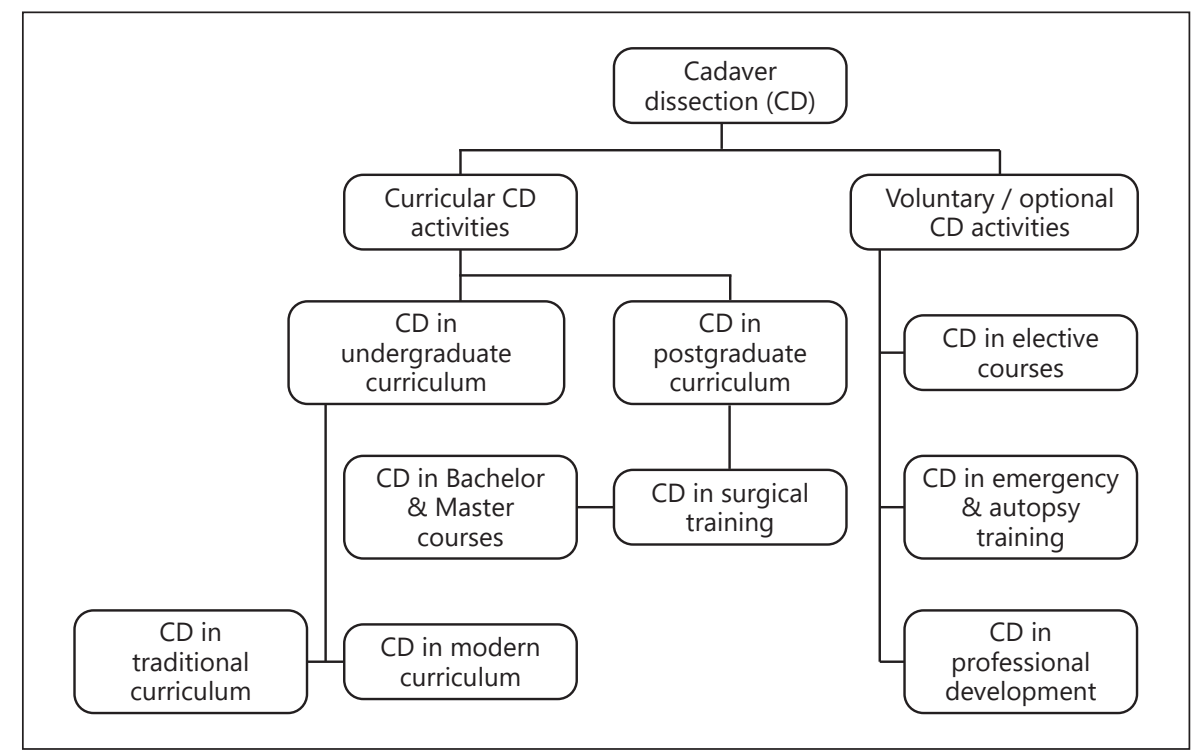

century and by the 18th century, it had become an essential component of medical education [2]. CD remained an integral part of the undergraduate medical curriculum until 2-3 decades ago and was mostly carried out in the initial years of medical training [2]. A revolution then started in the medical curriculum, aimed at decreasing expenses, removing redundancies, and making it more clinical [3]. In modernized versions of the curriculum, anatomy became the most compromised of the basic medical science subjects. This was particularly true for $\mathrm{CD}$, which was reduced substantially, limited to prosections, or removed completely [4]. Conflicting opinions in favor of/against $\mathrm{CD}$ have been reported in the literature $[5,6]$. The aim of this review is to determine the status of $\mathrm{CD}$ at different stages of medical training from the undergraduate to the postgraduate level. Placement, reallocation, and the importance of CD at curricular and voluntary/optional levels are also discussed. Briefly, in current medical curricula, traditional CD has been reduced but is still practiced in modified forms which we explain in this article.

\section{Literature Search}

This is a narrative overview. Published literature in English on relevant topics was searched on PubMed, Google Scholar, Ancestry, Ingentaconnect, ResearchGate, and FreeFullPDF. The following key words, either individually or in combination, were used for the search: "human cadaver dissection," "traditional and modern anatomy curriculum," "anatomy teaching," "anatomy practical lab," "cadaver dissection in surgery training and post-graduation courses," "elective and special courses of cadaver dissection," and "training workshops on cadaver dissection." Studies concerning anatomy teaching with $\mathrm{CD}$ in the medical curriculum and as a voluntary/optional activity, published in 1990-2017, were included. After screening the abstracts, about 200 articles were found to be relevant to our review and their full texts were read. Studies on the same topics published in other languages were excluded. The main ideas from the selected papers were extracted and are discussed here. I also share my personal and anecdotal experiences from colleagues. The status of CD in the medical curriculum and as voluntary/ optional (VOCD) activities is illustrated as an organogram in Figure 1.

\section{Current State of CD in Medical Training}

\section{CD in the Traditional Undergraduate Curriculum}

In the traditional undergraduate medical curriculum, teaching anatomy with CD remains important to many students [7], and so CD has therefore continued as a significant part of anatomy teaching over the last 4 centuries. Recently, in the past 2-3 decades, several medical schools have reduced or stopped dissection in undergraduate teaching [8]. Despite this, published literature from different continents has shown that CD is still practiced in 
Table 1. Examples of institutions that include cadaver dissection in the traditional undergraduate medical curriculum

\begin{tabular}{|c|c|c|}
\hline Institution & Country & Reference \\
\hline University of Nairobi & Kenya & {$[12]$} \\
\hline Methodist University & Kenya & {$[12]$} \\
\hline Ambrose Alli University & Nigeria & {$[10]$} \\
\hline University of Gondar & Ethiopia & {$[11,14]$} \\
\hline Mount Sinai School of Medicine & USA & [13] \\
\hline St. George’s Medical School & Grenada & {$[14]$} \\
\hline National University of Cordoba & Argentina & {$[5]$} \\
\hline University of Toronto & Canada & {$[18]$} \\
\hline McGill University & Canada & {$[18]$} \\
\hline University of British Columbia & Canada & {$[18]$} \\
\hline University of Saskatchewan ${ }^{1}$ & Canada & {$[18]$} \\
\hline Santosh Medical College & India & {$[19,20]$} \\
\hline University of Sri Jayewardenepura & Sri Lanka & {$[21]$} \\
\hline Dhaka Medical College (and others) & Bangladesh & {$[22]$} \\
\hline Nanjing Medical University & China & {$[23]$} \\
\hline Seoul National University College of Medicine & Korea & {$[24]$} \\
\hline Naresuan University & Thailand & {$[25]$} \\
\hline $\begin{array}{l}\text { Islamabad Medical and Dental College, Abbottabad Northern } \\
\text { Institute of Medical Sciences, and others }\end{array}$ & Pakistan & {$[26,27]$} \\
\hline Jundi Shapour University of Medical Sciences & Iran & {$[31,32]$} \\
\hline College of Medicine, King Saud University, Riyadh & Saudi Arabia & [29] \\
\hline Fukushima Medical University & Japan & {$[32]$} \\
\hline Guy's, King's, and St. Thomas' School of Biomedical Science & UK & {$[33]$} \\
\hline University of Leicester ${ }^{1}$ & UK & {$[15]$} \\
\hline University of East Anglia ${ }^{1}$ & UK & {$[3]$} \\
\hline Brighton and Sussex Medical School & UK & {$[15]$} \\
\hline School of Medicine and Medical Science ${ }^{1}$ & Ireland & {$[35]$} \\
\hline Otto von Guericke University Magdeburg & Germany & {$[36]$} \\
\hline Graz Medical School & Austria & {$[38]$} \\
\hline University of the Witwatersrand, Johannesburg & South Africa & {$[38]$} \\
\hline
\end{tabular}

the undergraduate curriculum, albeit in modified and integrated forms.

Today, Africa and the USA are the leading geographic areas in which medical schools offer CD. In Africa, 90\% of medical schools [9-12], and also in North and South America, a large majority [5, 13-15] offer CD in their undergraduate curricula. A survey involving 65 medical schools in the USA indicated the inclusion of dissection in most anatomy teaching programs $[16,17]$. In Canada, several medical schools have retained mandatory dissection in their undergraduate medical curriculum; the University of Saskatchewan offers optional dissection to interested students [18].

In Asia, data regarding $\mathrm{CD}$ are not available from most of the medical schools. However, the literature shows that, in India [19, 20], Sri Lanka [21], Bangladesh [22], China [23], Korea [24], and Thailand [25], many medical schools continue teaching anatomy assisted by CD. I have worked at an Anatomy Faculty in Pakistan for $>15$ years in the public and private sectors. Anecdotal evidence suggests that the majority of medical schools, particularly in the public sector, have continued with the traditional curriculum and use prosections and plastic models in anatomy laboratory teaching, but that only some of them offer CD $[26,27]$. Some medical schools in Saudi Arabia [28, 29], Iran [30, 31], and Japan [32] also use CD in anatomy teaching.

In European countries, traditional CD is not overwhelmingly used. Nonetheless, well-known medical schools in the UK [14, 33], Ireland [34], France [35], and 
Table 2. Examples of institutions that include cadaver dissection (CD) in the modern undergraduate medical curriculum, in bachelors, diploma, masters courses, and in surgical training programs

\begin{tabular}{llll}
\hline CD activity & Institution & Country & Reference \\
\hline Modern & University of Melbourne & Australia & {$[7]$} \\
undergraduate & Universities of Otago and Auckland & New Zeeland & {$[38]$} \\
curriculum & Alfaisal University & Saudi Arabia & {$[28]$} \\
& New York University & USA & {$[41]$} \\
& University of California (San Francisco and Davis) $)^{1}$ & USA & {$[41]$} \\
& University of Hawaii ${ }^{1}$ & USA & {$[42]$} \\
& University of Washington ${ }^{1}$ & USA & {$[42]$} \\
\hline Bachelors, diploma, & Cardiff University (BSc) & UK & {$[50]$} \\
and masters & University of Dundee & UK & {$[48]$} \\
& University of Otago & New Zealand & {$[47]$} \\
& The Wayne State University USA (MSc) & USA & {$[49]$} \\
& University of Nairobi & Kenya & {$[49]$} \\
\hline Surgical training & Wolfson Surgical Skills Centre & UK & {$[73]$} \\
& The Royal College of Surgeons & UK & {$[56]$} \\
& The Newcastle-upon-Tyne Hospitals & UK & {$[55]$} \\
& Otago School of Medical Sciences & New Zealand & {$[66]$} \\
& Universities of Sydney and Melbourne & Australia & {$[58]$} \\
& Clinical Training and Evaluation Centre & Australia & {$[59]$}
\end{tabular}

Germany [36] offer CD in anatomy teaching. The University of East Anglia, UK [3], and many medical schools in Australia offer optional dissection [37]. The details of some of the institutions continuing with CD in their traditional curriculum are given in Table 1.

A recent report by subject experts from Austria, Brazil, Colombia, India, New Zealand, Nigeria, Spain, South Africa, the USA, and Uruguay, confirms the presence of CD in different forms and formats in undergraduate curricula in their institutions [38]. Thus, collective data indicate that $\mathrm{CD}$ in the undergraduate curriculum has continued in many institutions across the world.

\section{CD in the Modern Undergraduate Curriculum}

Several institutions around the world have introduced modern integrated curricula by introducing problembased learning (PBL), case-based learning (CBL), teambased learning (TBL), and other computer-assisted teaching methods along with CD in undergraduate anatomy teaching $[6,28,39,40]$. The medical curriculum is not static. It takes many years for changes to be incorporated into the curriculum, and even more to decide if their outcomes are beneficial. For instance, some medical schools either reduced or abolished $\mathrm{CD}$, but feedback from fac- ulty and students, and concerns raised by surgeons, resulted in its reintegration into the clinical context and modern teaching methods [40-42]. Recent studies also recommend integrating $\mathrm{CD}$ into the modern curriculum [43], but some medical schools offer CD to students only when they are in their clinical rotation/internship [44]. In addition, $\mathrm{CD}$ is found to be beneficial in integrated teaching approaches for histopathology training [45]. Details of institutions conducting anatomy teaching with $\mathrm{CD}$ in the modern curriculum are given in Table 2.

\section{CD in Diploma and Masters Programs}

Medical graduates can further continue their careers on either a teaching or a clinical track. In teaching careers, graduates can pursue diploma, masters, MPhil, or PhD programs, while on the clinical side, they can pursue residency training in surgery or medicine. It is noteworthy that where there has been a lack of CD in undergraduate medical education, it has been compensated for in postgraduate training. Such training methods are practiced in Europe, Australia, New Zealand, the USA, and Africa, where medical schools strengthen the anatomical skills of their students in postgraduate programs using CD [4650]. Anecdotally, in Pakistan, CD is offered in programs 
such as MPhil in Anatomy. Details of the above are presented in Table 2 .

\section{CD in Surgical Training}

Highlighting the need for CD, Oliver Beahrs, a surgeon of international repute and the first President of the American Association of Clinical Anatomists, asserted: “... today's residents in surgery are learning their anatomy on sick patients for the first time in the middle of the night: operating without a firm knowledge of anatomy leads to increased mortality and morbidity" [51]. During the succeeding years, Ellis [52], Pawlina and Lachman [53], Regenbogen et al. [54], Holland et al. [55], and many other surgeons, anatomists, and medical educationalists also raised this issue and emphasized the significance of $\mathrm{CD}$ in medical and surgical training. In order to overcome these deficiencies, many institutions in the UK [55, 56], New Zealand [57], Australia [58, 59], and the USA $[60,61]$ have recommended and/or included additional dissection programs of specific body parts in their surgical residency programs. Details of the institutions offering $\mathrm{CD}$ in surgery training are given in Table 2.

\section{Voluntary/Optional CD}

VOCD refers to $C D$ activities which are not necessary for passing examinations or qualifying with a degree, and if someone practices CD in extracurricular sessions, it is not credited in his/her course work. To fulfill the need for $\mathrm{CD}$ amongst interested students, many institutions offer extra CD courses. These training sessions provide opportunities for hands-on practice to dissect the specific regions/parts of the body and learn emergency procedures. VOCD training activities, such as CD in elective courses, in the learning of emergency and autopsy procedures, and in continuous professional development sessions, are optional and not actually a part of the curriculum.

\section{CD in Elective Courses}

Accepting the significance of dissection, Warwick University in the UK created an anatomy exchange program with St. George's University, Grenada, which was a voluntary activity [14]. In 2011, the Sydney Medical School, Australia, reintroduced a 7-week elective wholebody CD course [46]. Medical schools in Australia, New Zealand, Kuwait, and Saudi Arabia have also started CD as a voluntary activity [62-64]. Ohio State University in the USA has implemented elective programs with interactive $\mathrm{CD}$ for medical students in different surgical specialties [65]. Charles University in Prague, Czech Republic, uses cadavers for teaching practical endoscopic methods to undergraduate and postgraduate students [66]. I would like to note that Aga Khan University in Pakistan offered intermittent elective CD courses during the summer vacations in 2003-2011. Details are given in Table 3.

\section{$C D$ in the Learning of Emergency and Autopsy Procedures}

Emergency clinical procedures such as lumbar puncture, cricothyrotomy, paracentesis, gastric lavage, and venesection require a detailed knowledge of human anatomy; CD and demonstrations provide an ideal opportunity to learn such skills [67]. In this context, the University of California, USA, in addition to its online training, uses hands-on practice with unembalmed cadavers for teaching emergency procedures [68]. Autopsy is a pathological dissection procedure of medicolegal importance. In order to learn and keep updated about anatomy and dissection skills over time, it is essential for medical students and practicing physicians to acquire autopsy skills [69]. During autopsies, trainees avail the opportunity of dissecting mostly fresh and unembalmed bodies [70]. In Japan, dissection of the human body is allowed only under special circumstances, such as medicolegal autopsies or for teaching in medical colleges. The anatomy departments of most universities in Japan provide the facilities for comedical training schools to observe $\mathrm{CD}$ as they acknowledge the importance of dissection [71]. Details are depicted in Table 3.

\section{CD in Continuous Professional Development Sessions}

Following the need and importance of CD in the subspecialties of surgery, radiology, and clinical practice, various institutions have started specialty-specific training courses on cadavers. These courses are in addition to their routine curricular residency training and conducted under the supervision of experts, providing a valuable opportunity for learning particular procedures and techniques. In this regard, many institutions arrange voluntary courses on CD for teaching modified surgical skills [72-76]. I note here that the neurosurgery, orthopedic surgery, and otolaryngology sections of the Surgery Department of Aga Khan University and many other institutions in Pakistan conduct specialty-specific training courses on cadavers. In Germany, a new "Theatrum anatomicum," similar to the ancient anatomical theatre provides an opportunity for learning anatomy and difficult surgical procedures outside the operating room by making use of cadavers [77]. In addition, many medical training centers conduct $\mathrm{CD}$ workshops in order to develop 
Table 3. Examples of institutions that include cadaver dissection (CD) in elective courses, emergency and autopsy training, and continuous professional development programs

\begin{tabular}{|c|c|c|c|}
\hline CD activity & Institution & Country & Reference \\
\hline \multirow[t]{9}{*}{ Elective courses } & Warwick University & UK & {$[14]$} \\
\hline & St. George's University, Grenada & Grenada & {$[14]$} \\
\hline & Charles University in Prague & Czech Republic & {$[66]$} \\
\hline & Sydney Medical School & Australia & {$[46]$} \\
\hline & Medical Schools & New Zealand & {$[62]$} \\
\hline & Kuwait University & Kuwait & {$[63]$} \\
\hline & Al Faisal University & Saudi Arabia & {$[64]$} \\
\hline & The Ohio State University & USA & {$[65]$} \\
\hline & Aga Khan University & Pakistan & this study ${ }^{1}$ \\
\hline $\begin{array}{l}\text { Emergency and } \\
\text { autopsy training }\end{array}$ & University of California & USA & {$[64]$} \\
\hline \multirow{6}{*}{$\begin{array}{l}\text { Continuous } \\
\text { professional } \\
\text { development }\end{array}$} & $\begin{array}{l}\text { European Academy of Facial Plastic Surgery, } \\
\text { Amsterdam }\end{array}$ & The Netherlands & {$[72]$} \\
\hline & "Theatrum anatomicum" & Germany & {$[77]$} \\
\hline & Wolfson Surgical Skill Centre & UK & {$[73]$} \\
\hline & $\begin{array}{l}\text { Centre of Anatomy and Cell Biology, Medical } \\
\text { University Vienna }\end{array}$ & Austria & {$[75]$} \\
\hline & $\begin{array}{l}\text { Duke Division of Plastic, Maxillofacial, and Oral } \\
\text { Surgery, and Docent LLC, Atlanta }\end{array}$ & USA & {$[90]$} \\
\hline & Surgery Department of Aga Khan University & Pakistan & this study ${ }^{1}$ \\
\hline
\end{tabular}

${ }^{1}$ As yet unpublished observations by the author.

new surgical procedures [78, 79]. The institutions conducting specialty-specific training courses on cadavers are shown in Table 3.

\section{Discussion}

This article presents the status of anatomy teaching with $\mathrm{CD}$ as parts of both the medical curriculum and VOCD. Curricular activity is categorized under both undergraduate and postgraduate curricula. Undergraduate anatomy teaching with CD is discussed as a part of traditional and modern curricula. In postgraduate programs, $\mathrm{CD}$ is discussed in the diploma, masters, and surgery training programs. Outside the curriculum, CD is presented in elective courses, the learning of emergency and autopsy procedures, and continuous professional development.

The literature indicates that many schools around the word have retained CD as part of anatomy teaching in their traditional undergraduate medical curricula. Some medical schools have integrated it vertically and/or with other basic science subjects. Some other medical schools offer optional dissection to interested students. Although the modern undergraduate medical curriculum started with cutting down on detailed anatomy teaching and $\mathrm{CD}$, the literature cited here shows that $\mathrm{CD}$ has either been continued or restarted with the PBL, CBL, and TBL methods of teaching. For modern teaching methods, CD has been integrated within the clinical context and aided by radiological images. Around the world, CD is also practiced in postgraduate programs (surgery training, diploma, bachelors, and masters in anatomy, etc.).

Deficiencies in physical examination skills and surgical procedures as well as the lack of anatomical knowledge for interpreting radiological images tempted experts to start dissection programs outside the curriculum. The published literature also shows that $\mathrm{CD}$ has been practiced in VOCD programs, such as elective dissection courses, learning emergency and autopsy procedures, and continuous professional development sessions.

Anatomy teaching with $\mathrm{CD}$ used to be a major component of the first 2 years of the undergraduate curriculum. As it is a time-consuming activity, other basic science subjects were compromised. This situation compelled the stakeholders to voice their concerns and 
demand a balanced allocation of time for the basic science subjects in the medical curriculum. However, the outcomes were different. Instead of a balanced reallocation of basic science subjects, several, but not all, medical schools reduced the time allocated for anatomy teaching. Simultaneously, they omitted or significantly condensed CD [80]. Within the span of approximately 2 decades, gaps in anatomical knowledge amongst graduating students became evident. General medical practitioners graduating from this era were found to be lacking in skills for performing simple medical procedures, which jeopardized the safety of patients [81]. This undesirable impact gave rise to new strategies which brought $\mathrm{CD}$ back, in conjunction with innovative teaching methods, and reallocated it in medical training [70].

As highlighted in the subsections " $\mathrm{CD}$ in the Traditional Curriculum" and "CD in the Modern Integrated Curriculum," a significant number of medical schools in the USA, Africa, and others around the world have continued with CD in their traditional, modern integrated, and hybrid undergraduate curricula. I agree with Inuwa et al. [82] that traditional and modern curricula can be taught together, instead of discarding the traditional methods of anatomy teaching. Additionally, many other techniques like radiographs, cadaver computed tomography (CT) scans, magnetic resonance imaging (MRI), ultrasound [44, 83, 84], computer media, CD ROM [20], and computer-aided holographic models [85] have been added to CD in anatomy teaching. These modifications, with some exceptions [86], have enhanced 3-dimensional perception and the understanding of the human body, thus moving closer to safe medical practice. I also agree with Yammine [61], Alyafi et al. [39], and Turney [87] that traditional methods, such as dissection and prosections, can meet many of the objectives of the PBL approach, like developing reasoning skills and learning, in a relevant context.

On the academic side, the shortage of anatomy teachers experienced in CD skills has increased [80, 88]. Thus, the teaching of anatomy by unskilled teachers has created a vicious cycle of producing more anatomy teachers and clinicians who are, however, less equipped with dissection and procedural skills $[8,16,42,87,89]$. To compensate for these deficiencies, diploma, bachelors, and masters courses in anatomy and/or basic sciences with CD have been recommended and introduced [59, 90]. Such programs have certainly helped in producing better anatomy teachers who can train medical students to be competent enough to cope with the needs of general medical practice and surgery training $[91,92]$. This scenario em- phasizes the importance of continuing anatomy teaching with $\mathrm{CD}$ in medical training. However, CD has partly shifted from the undergraduate to the postgraduate level.

On the clinical side, abandoning CD had a negative effect on the competency of future surgeons, ultimately compromising the safety of patients. This impelled surgeons and anatomists to raise their concerns and vouch for CD in medical training. They could not convince medical educationalists to resume $\mathrm{CD}$ the way it is practiced in the traditional curriculum, but they were able to incorporate it in surgical training programs. Furthermore, reallocation of CD at advanced levels, in conjunction with various modalities of radiology, imaging, cadaver CT slices, and modern electronic and digital techniques, enhanced the spectrum of $\mathrm{CD}$ in diagnosis and treatment $[44,57,93,94]$. The reorganization of CD from undergraduate teaching to surgical training programs has reinforced its validity in medical education.

In many countries of the world, it is within the scope of general medical practitioners employed in the public sector to conduct general medical procedures and perform autopsies. A sound knowledge of gross anatomy and dissection skills is essential for carrying out medical emergency procedures and autopsies. The importance and necessity of CD has thus continued to grow. Different institutions have added dissection at different levels in their undergraduate and postgraduate curricula, but the need for $\mathrm{CD}$ is undisputed. Therefore, in addition to reallocation of CD in the medical curricula, VOCD is also introduced into elective courses, the learning of emergency and autopsy procedures, and specialty-specific workshops (Table 3).

Many medical graduates continue their professional careers as general practitioners, some specialize in surgery- or medicine-allied fields, and the rest adopt teaching as a career. It is a common anecdotal argument that graduates who do not become surgeons or anatomy teachers do not need extensive dissection skills. However, in today's medical world, the subspecialties in intervention medicine, such as cardiology, gastroenterology, nephrology, and pulmonology, require a good knowledge of the human body for safe procedural practice. At the very least, a sound knowledge of anatomy would behove practitioners to understand patients' symptoms and relate them to the organs involved. This entire situation indicates that CD has actually not been abolished but rather integrated vertically in the undergraduate and postgraduate medical curricula, and is strengthened by the clinical scenario, radiology, and digital and other modern tools. 


\section{Limitations}

This review does not include any numerical data or statistical analysis, which could have strengthened its value and importance. Secondly, the inclusion of additional literature in other languages would have broadened the spectrum of the article.

\section{Conclusion}

Medical practitioners, surgeons, anatomy teachers, and researchers in the anatomical field cannot avoid CD if they wish to become competent professionals. They need CD skills to assist them in performing safe and sat- isfactory practices during their professional careers. Thus, it is not reasonable to conclude that $\mathrm{CD}$ is obsolete in medical training. I support the contention of Ghosh [95] that anatomy including CD should be incorporated vertically, in a reasonable manner, into medical education at the undergraduate and postgraduate levels as well as in internships, along with other modern teaching strategies.

\section{Acknowledgements}

I thank Dr. Dileep Rohra, Assoc. Prof., Alfaisal University, and Mr. Irfan Anjum, Assist. Prof., King Saud bin Abdulaziz University for Health Sciences, in Riyadh, Saudi Arabia, for their scholarly review and refinement of this article.

\section{References}

1 von Staden H: The discovery of the body: human dissection and its cultural contexts in ancient Greece. Yale J Biol Med 1992;65:223224.

2 Rath G, Garg K: Inception of cadaver dissection and its relevance in the present day scenario of medical education. J Indian Med Assoc 2006; 104:331-333.

3 Howe A, Campion P, Searle J, et al: New perspectives - approaches to medical education at four new UK medical schools. BMJ 2004; 329:327-331.

4 Rainsbury D, Barbour A, Mahadevan V: College launches national anatomy project. Ann R Coll Surg Engl 2007;89:19.

- 5 Biasutto SN, Caussa LI, Criado del Rio LE: Teaching anatomy: cadavers versus computers? Ann Anat 2006;188:187-190.

-6 Patel SB, Mauro D, Fenn J, Sharkey DR, et al: Is dissection the only way to learn anatomy? Thoughts from students at a non-dissectingbased medical school. Perspect Med Educ 2015;4:259-260.

7 Azer SA, Eizenberg N: Do we need dissection in an integrated problem-based learning medical course? Perceptions of first- and second-year students. Surg Radiol Anat 2007;29: 173-180.

$>8$ Korf HW, Wicht H, Snipes RL, et al: The dissection course - necessary and indispensable for teaching anatomy to medical students. Ann Anat 2008;190:16-22.

-9 Gangata H, Ntaba P, Akol P, et al: The reliance on unclaimed cadavers for anatomical teaching by medical schools in Africa. Anat Sci Educ 2010;3:174-183.

10 Izunya AM, Oaikhena GA, Nwaopara AO: Attitudes to cadaver dissection in a Nigerian medical school. Asian J Med Sci 2010;2:8994.
11 Bekele A, Reissig D, Loffler S, et al: Experiences with dissection courses in human anatomy: a comparison between Germany and Ethiopia. Ann Anat 2011;193:163-167.

12 Ongeti K: Pedagogical value of dissection anatomy in Kenya. Singapore Med J 2012;53: 712-714.

113 Reidenberg JS, Laitman JT: The new face of gross anatomy. Anat Rec 2002;269:81-88.

14 Chambers J, Emlyn-Jones D: Keeping dissection alive for medical students. Anat Sci Educ 2009;2:302-303.

15 Nwachukwu C, Lachman N, Pawlina W: Evaluating dissection in the gross anatomy course: correlation between quality of laboratory dissection and students outcomes. Anat Sci Educ 2015;8:45-52.

16 Drake RL, McBride JM, Lachman N, et al: Medical education in the anatomical sciences: the winds of change continue to blow. Anat Sci Educ 2009;2:253-259.

17 Der Bedrosian J: First-year medical students still rely on cadavers to learn anatomy. Johns Hopkins Magazine, Johns Hopkins University, 2016 https://hub.jhu.edu/magazine/ 2016/winter/cadavers-anatomy-medicalschool/ (accessed 2 January 2018).

18 Grant K: Dissection debate: why are medical schools cutting back on cadavers? http:// www.theglobeandmail.com/life/health-andfitness/health/dissection-debate-why-aremedical-schools-cutting-back-on-cadavers/ article18296300/ (accessed 15 December 2014).

19 Sharma N: Teaching of human anatomy in India: the Indian perspective. Missing the woods for the trees? Rev Arg Anat Clin 2014; 6:6-8.

20 Arora L, Sharma BR: Assessment of role of dissection in anatomy teaching from the perspective of undergraduate students: a qualitative study. Ibnosina J Med BS 2011;3:59-65.
21 Weerasuriya T, Chan F, Yasawardene S, et al: Preference of medical students of formaldehyde-preserved cadaveric dissection versus pre-dissected specimens as a teaching tool in human anatomy. J Med Res 2014;2014:1-6.

22 Nurunnabi AM, Ara S, Khalil M, et al: Ethics in dissection of cadaver in teaching and learning of anatomy. Bangladesh J Bioethics 2011; 2:10-15.

23 Zhang L, Xiao M, Gu M, et al: An overview of the roles and responsibilities of Chinese medical colleges in body donation programs. Anat Sci Educ 2014;7:312-320.

24 Kang SH, Shin JS, Hwang YI: The use of specially designed tasks to enhance student interest in the cadaver dissection laboratory. Anat Sci Educ 2012;5:76-82.

25 Winkelmann A, Güldner FH: Cadavers as teachers: the dissecting room experience in Thailand. BMJ 2004;329:1455-1457.

26 Naz S, Nazir G, Iram S, et al: Perceptions of cadaveric dissection in anatomy teaching. J Ayub Med Coll Abbottabad 2011;23:145148

27 Khan HM, Mirza TM: Physical and psychological effects of cadaveric dissection on undergraduate medical students. J Pak Med Assoc 2013;63:831-834.

28 Cowan M, Arain NN, Assale TS, et al: Student-centered integrated anatomy resource sessions at Alfaisal University. Anat Sci Educ 2010;3:272-275.

29 Vohra MS: Personal formaldehyde exposure level in the gross anatomy dissecting room at the College of Medicine King Saud University Riyadh. Int J Occup Med Environ Health 2011;24:108-113.

30 Javadnia F, Hashemitabar M, Kalantarmahdavi SR, et al: How to decrease the emotional impact of cadaver dissection in medical students. Pak J Med Sci 2006;22:200-203. 
-31 Hassanzadeh G, Narges Hassanpoor N, Jalali A, et al: Teaching anatomy: viewpoints of Iranian anatomists. Thrita J Med Sci 2012;1:6266.

32 Murakami T, Tajika Y, Ueno H, et al: An integrated teaching method of gross anatomy and computed tomography radiology. Anat Sci Educ 2014;7:438-449.

33 Ali A, Khan ZN, Konczalik W, et al: The perception of anatomy teaching among UK medical students. RCS bulletin 2015;97:397-400.

34 Cahill KC, Ettarh RR: Attitudes to anatomy dissection in an Irish medical school. Clin Anat 2009;22:386-391.

- 35 Ropars M, Haegelen C, Najihi N, et al: Analytic study of hopes and perceptions of second-year medical school students during gross anatomy laboratory sessions. Morphologie 2011;95:60-64.

- 36 Bernhardt V, Rothkötter HJ, Kasten E: Psychological stress in first year medical students in response to the dissection of a human corpse. GMS Z Med Ausbild 2012;29:doc12.

-37 Eppler E, Serowy S, Link K, et al: Experience from an optional dissection course in a clinically orientated concept to complement system-based anatomy in a reformed curriculum. Anat Sci Educ 2017, DOI: 10.1002/ ase.1707.

- 38 Biasutto SN, Sharma N, Weiglein AH, et al: Human bodies to teach anatomy: importance and procurement - experience with cadaver donation. Rev Arg Anat Clin 2014;6:72-86.

- 39 Alyafi MM, Alamodi AA, Juurlink BH, et al: How the dissection laboratory facilitates integration of learning: presence of abdominal aortic aneurysm with a large intracardiac thrombus: a rare cadaver finding. Int J Angiol 2012;21:77-80.

40 Huitt TW, Killins A, Brooks WS: Team-based learning in the gross anatomy laboratory improves academic performance and students' attitudes toward teamwork. Anat Sci Educ 2015;8:95-103.

41 Patel KM, Moxham BJ: Attitudes of professional anatomists to curricular change. Clin Anat 2006;19:132-141.

42 Rizzolo LJ, Stewart WB: Should we continue teaching anatomy by dissection when ...? Anat Rec B New Anat 2006;289:215-218.

43 Pais D, Casal D, Mascarenhas-Lemos L, et al: Outcomes and satisfaction of two optional cadaveric dissection courses: a 3-year prospective study. Anat Sci Educ 2017;10:127-136.

-44 Nwachukwu CR: Cadaver CT scans a useful adjunct in gross anatomy: the medical student perspective. Anat Sci Educ 2014;7:83-84.

45 Gopalan V, Dissabandara L, Nirthanan S, et al: Integrating gross pathology into teaching of undergraduate medical science students using human cadavers. Pathol Int 2016;66: 511-517.

-46 Burgess AW, Ramsey-Stewart G, May J, et al: Team-based learning methods in teaching topographical anatomy by dissection. ANZ J Surg 2012;82:457-460.
47 Stringer MD, Lyall P: Design, implementation, and evaluation of a postgraduate diploma in surgical anatomy. Anat Sci Educ 2012; 5:48-54.

48 Eisma R, Lamb C, Soames RW: From formalin to Thiel embalming: what changes? One anatomy department's experiences. Clin Anat 2013;26:564-571.

49 Ogeng'o J, Ongeti K, Misiani M, et al: Maintaining excellence in teaching of human anatomy: University of Nairobi experience. Anat J Afr 2013;2:117-129.

50 Kwan A: Biomedical Sciences (Anatomy) with a preliminary year and professional training year (BSc). http://courses.cardiff.ac. uk/undergraduate/detail/bcd7.html (accessed 16 December 2014).

51 Green NA: Anatomy training for surgeons - a personal viewpoint. J R Coll Surg Edinb 1998; 43:69-70.

52 Ellis H: Medico-legal litigation and its links with surgical anatomy. Surgery 2002;20:i-ii.

53 Pawlina W, Lachman N: Dissection in learning and teaching gross anatomy: rebuttal to McLachlan. Anat Rec B New Anat 2004;281: 9-11.

54 Regenbogen SE, Greenberg CC, Studdert DM, et al: Patterns of technical error among surgical malpractice claims: an analysis of strategies to prevent injury to surgical patients. Ann Surg 2007;246:705-711.

55 Holland JP, Waugh L, Horgan A, et al: Cadaveric hands-on training for surgical specialties: Is this back to the future for surgical skills development? J Surg Educ 2011;68:110-116.

56 Rainsbury RM: Supporting modern postgraduate surgical training programs in the United Kingdom. Eur J Anat 2007;11:105-109.

57 Cornwall J, Stringer MD: Are computed tomography scans of cadavers perceived as a useful educational adjunct in a surgical anatomy course? Anat Sci Educ 2014;7:77.

58 Stewart F, West R: Gross topographical anatomy by dissection for basic surgical training candidates: development and implementation of a course at University of Sydney. ANZ J Surg 2002;72:A98.

59 Jansen S, Kirk D, Tuppin K, et al: Fresh frozen cadavers in surgical teaching: a gelatine arterial infusion technique. ANZ J Surg 2011;81: 880-882.

60 Lewis CE, Peacock WJ, Tillou A, et al: A novel cadaver-based educational program in general surgery training. Surg Educ 2012;69:693698.

61 Yammine K: The current status of anatomy knowledge: where are we now? Where do we need to go and how do we get there? Teach Learn Med 2014;26:184-188.

62 Craig S, Tait N, Boers D, et al: Review of anatomy education in Australian and New Zealand medical schools. ANZ J Surg 2010;80: 212-216.

63 Khan KM: Anatomy education at the Faculty of Medicine of Kuwait University. Med Princ Pract 2010;19:418.
64 Yaqinuddin A, Ikram MF, Zafar M, et al: The integrated clinical anatomy program at $\mathrm{Al}$ faisal University: an innovative model of teaching clinically applied functional anatomy in a hybrid curriculum. Adv Physiol Educ 2016;40:56-63.

65 Haubert LM, Jones K, Moffatt-Bruce SD: Surgical clinical correlates in anatomy: design and implementation of a first-year medical school program. Anat Sci Educ 2009;2:265272.

66 Doubková, A, Smrzová T: Practical endoscopic methods education in the Educational Center for Anatomy and Endoscopy of the Department of Anatomy, Third Faculty of Medicine, Charles University in Prague - is there room for further progress? Cas Lek Cesk 2008;147:487-489.

67 Boon JM, Meiring JH, Richards PA: Clinical anatomy as the basis for clinical examination: development and evaluation of an introduction to clinical examination in a problem-oriented medical curriculum. Clin Anat 2002;15: 45-50.

68 Tabas JA, Rosenson J, Price DD, et al: A comprehensive, unembalmed cadaver-based course in advanced emergency procedures for medical students. Acad Emerg Med 2005;12: 782-785

69 Goyal PK, Gupta M, Kaur J: Autopsy as a tool for learning gross anatomy during 1st year MBBS. Int J Appl Basic Med Res 2016;6:230232.

70 Sugand K, Abrahams P, Khurana A: The anatomy of anatomy: a review for its modernization. Anat Sci Educ 2010;3:83-93.

71 Sakai T: Body donation: an act of love supporting anatomy education. JMAJ 2008;51: 39-45.

72 The 21st International Course in Modern Rhinoplasty Techniques http://www.rhinoplastycourse.nl/cadaver-dissection. Impressions 2014.

73 Royal College of Surgeons, England: Annual report 2007-2008. http://www.rcseng.ac.uk/ publications/...ffile/RCS (accessed 17 December 2014).

74 Mitchell EL, Sevdalis N, Arora S, et al: A fresh cadaver laboratory to conceptualize troublesome anatomic relationships in vascular surgery. J Vasc Surg 2012;55:1187-1194.

75 Traxler H, Fock N: Vienna hands-on-courses defining post graduate anatomical-surgical training since 1997. www.anatomical-surgical-training.com (accessed 17 December 2014)

76 Zenn MR: Thirteenth annual fresh cadaver flap dissection course. http://plastic.surgery. duke.edu/flapcourse (accessed 16 December 2014).

77 Boeckers A, Fassnacht U, Boeckers TM: "Theatrum anatomicum" - a revived teaching facility in gross anatomy. Ann Anat 2008; 190 : 495-501. 
78 Clemente FR, Fabrizio PA, Shumaker M: A novel approach to the dissection of the human knee. Anat Sci Educ 2009;2:41-46.

79 Becker AM, Hwang PH: Endoscopic endonasal anatomy of the nasopharynx in a cadaver model. Int Forum Allergy Rhinol 2013;3:319324.

80 McLachlan JC, Patten D: Anatomy teaching: ghosts of the past, present and future. Med Educ 2006;40:243-253.

81 Warner JH, Rizzolo LJ: Anatomical instruction and training for professionalism from the 19th to the 21st centuries. Clin Anat 2006;19: 403-414.

82 Inuwa I, Taranikanti $\mathrm{V}, \mathrm{Al}$-Rawahy $\mathrm{M}$, et al: "Between a rock and a hard place": the discordant views among medical teachers about anatomy content in the undergraduate medical curriculum. Sultan Qaboos Univ Med J 2012;12:19-24.
3 Bohl M, Francois W, Gest T: Self-guided clinical cases for medical students based on postmortem CT scans of cadavers. Clin Anat 2011;24:655- 663.

84 Phillips AW, Smith SG, Straus CM: The role of radiology in preclinical anatomy: a critical review of the past, present, and future. Acad Radiol 2013;20:297-304.

85 Miller M: Use of computer-aided holographic models improves performance in a cadaver dissection-based course in gross anatomy. Clin Anat 2016;29:917-924.

86 Lufler RS, Zumwalt AC: Imaging the cadavers being dissected does not appear to improve the gross anatomy dissection experience. Anat Sci Educ 2014;7:78-79.

87 Turney BW: Anatomy in a modern medical curriculum. Ann R Coll Surg Engl 2007;89: 104-107.

88 Habbal O: The state of human anatomy teaching in the medical schools of gulf cooperation council countries: present and future perspectives. Sultan Qaboos Univ Med J 2009;9:2431.
89 McLachlan JC: New path for teaching anatomy: living anatomy and medical imaging versus dissection. Anat Rec 2004;281:4-5.

90 Standring S: New focus on anatomy for surgical trainees. ANZ J Surg 2009;79:114-117.

91 Lachman N, Pawlina W: Integrating professionalism in early medical education: the theory and application of reflective practice in the anatomy curriculum. Clin Anat 2006; 19: 456-460.

92 Fraher JP, Evans DJ: Training tomorrow's anatomists today: a partnership approach. Anat Sci Educ 2009;2:119-125.

93 Collins JP: Modern approaches to teaching and learning anatomy: BMJ 2008;337:a131.

94 Jiménez AM, Aguilar JF: Laparoscopy: learning a new surgical anatomy? Anat Sci Educ 2009;2:81-83.

95 Ghosh SK: Cadaveric dissection as an educational tool for anatomical sciences in the 21st century. Anat Sci Educ 2017;10:286-299. 